\title{
Perforated colorectal cancers: clinical outcomes of 18 patients who underwent emergency surgery
}

\author{
Mehmet Ali Gök ${ }^{1}$, Mehmet Tolga Kafadar ${ }^{2}$, Serkan Fatih Yeğen ${ }^{3}$ \\ ${ }^{1}$ Clinic of General Surgery, Health Sciences University, Derince Training and Research Hospital, Kocaeli, Turkey \\ 2Department of General Surgery, School of Medicine, Dicle University, Diyarbakır, Turkey \\ ${ }^{3}$ Clinic of General Surgery, Ali Osman Sönmez Oncology Hospital, Bursa, Turkey
}

Gastroenterology Rev 2021; 16 (2): 161-165

DOI: https://doi.org/10.5114/pg.2021.106667

Key words: colorectal cancers, perforation, emergency surgery, mortality.

Address for correspondence: Mehmet Tolga Kafadar MD, Department of General Surgery, School of Medicine, Dicle University, Diyarbakır, Turkey, phone: +90 4122488001, e-mail: drtolgakafadar@hotmail.com

\begin{abstract}
Introduction: Although colon cancer perforations are rare among acute abdominal syndromes, it is a clinical picture with high mortality that requires urgent treatment.

Aim: In this study, the clinical results of patients who were operated in emergency conditions due to colorectal cancer perforation were evaluated.

Material and methods: The data of 18 patients treated for colorectal cancer perforation in our clinic between February 2014 and February 2017 were retrospectively reviewed. The following data were evaluated: demographic features of the patients, location of the tumour, metastasis, stage of the tumour, number of lymph nodes dissected, survival, type, and prognosis of the surgery.

Results: Eight (44\%) of 18 patients with perforated colon cancers were female and 10 (56\%) were male. The mean age was 65.2 (31-104) years. Four of the patients had liver metastasis only, and 5 had multiple metastases. All cases had sudden abdominal pain and acute abdominal clinical findings. Fourteen of the patients underwent full resection, and 4 of them underwent partial resection and trephine stoma (colostomy). Perioperative mortality was not observed. The long-term mortality rate in our study was $77.7 \%(n=14)$, and the operative mortality rate was $44 \%(n=8)$. Additional organ injuries occurred during resection in 2 patients.

Conclusions: Colorectal cancer perforation seen in advanced ages is one of the causes of acute abdominal syndrome, which can be fatal. The general condition of the patient and the size and localization of the perforation should be taken into consideration in the choice of treatment. Curative surgery can also be performed in perforated colorectal cancers. However, partial resection and trephine colostomy should be performed in patients with multiple metastases and poor general condition.
\end{abstract}

\section{Introduction}

Mortality in colorectal surgeries performed under emergency conditions is higher than in elective surgeries. Perforated colon cancers are rarely seen among the causes of acute abdominal syndrome but have a high mortality rate. In recent years, an increase in colorectal cancer perforations has been observed [1]. Faecal peritonitis, which develops as a result of gastrointestinal contamination in the abdominal cavity, requires urgent surgical intervention due to its mortality. The perforated colonic segment should be resected to prevent the patient from being exposed to faecal contents. This resection is necessary for faecal content, as well as for tumour cells not to spill into the abdominal cavity [2]. The general condition of the patient, advanced age, concomitant diseases, the degree of spreading of the faecaloma, and the localization and size of the perforation seriously affect the prognosis. Mortality rates in these patients are much higher compared to patients with colorectal cancer who have been operated urgently or electively due to mechanical bowel obstruction [3]. One of the biggest problems in these patients is delayed diagnosis. Sepsis and related complications cause the general condition of the patient to worsen and the mortality rate to increase [4]. The choice of surgical procedures in these patients is still controversial. 


\section{Aim}

In this study, we presented the clinical results of patients who were operated in emergency conditions due to colorectal cancer perforation.

\section{Material and methods}

The data of patients admitted to Kartal Dr Lütfi Kırdar Training and Research Hospital, Istanbul, Turkey with acute abdominal syndrome due to colorectal cancer perforation between February 2014 and February 2017 were retrospectively analysed. All cases had sudden abdominal pain and acute abdominal clinical findings. Computed tomography was performed in all cases in the emergency service. Patients' age, gender, localization of the tumour, location of perforation, pathology results, number of lymph nodes dissected, surgical margin, presence of residual tissue, distant metastasis, method of surgery, surveys, mortality and morbidity rates, and perioperative complications were determined. Surgical intervention was performed in all patients following preoperative third-generation cephalosporin prophylaxis. American Society of Anesthesiologists (ASA) scoring was evaluated for risk assessment. Patients who died within 30 days postoperatively were defined as "operative mortality".

\section{Ethics Committee Approval}

Authors declared that the research was conducted according to the principles of the World Medical Association Declaration of Helsinki "Ethical Principles for Medical Research Involving Human Subjects”.

\section{Statistical analysis}

To determine the factors affecting mortality and morbidity, risk factors were identified and grouped first. Statistical differences between groups were analysed using the $\chi^{2}$ test. For those with a statistically significant difference in these tests, logistic regression testing was applied and factors affecting mortality and morbidity were determined. When $p<$ 0.05 was found in all statistical studies, the result was considered significant. The statistical analyses were performed using SPSS (Statistical Package for the Social Sciences ver. 11.5, SPSS Inc, Chicago, Illinois, USA) computer software.

\section{Results}

Eight (44\%) of the 18 patients were female and 10 (56\%) were male. The mean age was 65.2 (31-104) years. All cases had sudden abdominal pain and acute abdominal clinical findings. When the patients were admitted to the emergency clinic, the mean white blood cells (WBC) count was $17.400 / \mathrm{mm}^{3}$ (7400-28000) and the mean level of C-reactive protein was $12.1 \mathrm{mg} / \mathrm{l}$ (6.2-24.9). Fourteen patients were ASA-4 and 4 were ASA-3. The most common location of tumours was the rectosigmoid junction. In 8 (44\%) cases, the tumour was in the sigmoid colon, 7 (38.8\%) in the cecum, $1(0.5 \%)$ in the hepatic flexure, and $2(1.1 \%)$ in the splenic flexure. Two (11\%) of the cases were reoperated due to recurrent rectal cancer. The mean number of lymph nodes dissected was 12.4 (2-26). In 7 (38.8\%) cases, the number of metastatic lymph nodes was between 1 and 3 (N1), and 11 (61.1\%) had more than 3 (N2). In $3(16.6 \%)$ of the resected cases, the surgical margin was positive. Perioperative mortality was not observed. While primary tumour was resected in 14 (77.57\%) cases, trephine colostomy was performed in 4 cases in which resection was not possible. In 6 (33\%) patients residual tumours were left. In 10 (56\%) cases primary intestinal anastomosis was performed after resection. In 8 of the cases undergoing anastomosis a protective ileostomy was performed. Postoperative anastomosis leakage was observed in $2(20 \%)$ of 10 cases with primary anastomosis. There was no protective ileostomy in 2 patients with anastomosis leak. Distant metastasis was present in 8 (44\%) of the cases. All of the cases were T4 tumours. Perioperative additional organ injuries developed in 2 cases. One patient had left renal vein injury, and so primary vascular repair was performed. Splenic injury occurred in 1 patient, and so splenectomy was performed. None of the patients underwent liver resection or metastasectomy. The postoperative morbidity rate was $27.7 \%(n=5)$. Postoperative mortality developed in $8(44 \%)$ of the cases. In $7(38.8 \%)$ cases the cause of postoperative mortality was sepsis and multiple organ failure, while in $1(5.5 \%)$ case it was acute thromboembolism. Postoperative mortality was observed in 4 (50\%) of 8 cases without gastrointestinal anastomosis and in 4 (40\%) of 10 cases with anastomosis $(p=0.602)$. Tumour resection was performed in all of the resectable cases. Postoperative mortality was observed in 2 of 4 nonresectable cases ( $p=0.043$ ). Histopathological examination of all patients was evaluated as adenocarcinoma. Eight (44\%) of the patients received chemotherapy when they applied to the emergency department. Two received neoadjuvant radiotherapy. The clinical features of the cases are shown in Tables I and II.

\section{Discussion}

Colorectal cancers are among the most common tumours of the gastrointestinal tract. The most common cause of colon perforations (58-63\%) is colon diverticulum, and the second most common cause is colon 
Table I. Characteristics and surgical procedures of the patients

\begin{tabular}{|c|c|c|c|c|c|c|c|c|}
\hline $\begin{array}{l}\text { Age } \\
\text { gender }\end{array}$ & ASA & Residue tm & Anastomosis & $\begin{array}{l}\text { Protective } \\
\text { ileostomy }\end{array}$ & Stage & $\mathrm{CT}$ & RT & Additional organ injury \\
\hline $61 M$ & 4 & Unresectable & - & - & Multiple metastasis & + & + & - \\
\hline $78 \mathrm{~F}$ & 4 & + & + & + & $\mathrm{T} 4$ & - & - & $\begin{array}{l}\text { Small bowel serosa } \\
\text { injury + splenectomy }\end{array}$ \\
\hline $60 M$ & 4 & - & + & - & $\mathrm{T} 4$ & - & - & - \\
\hline $87 \mathrm{~F}$ & 4 & + & - & - & $\begin{array}{l}\text { T4 + Hepatic } \\
\text { metastasis }\end{array}$ & - & - & Left renal vein injury \\
\hline $104 \mathrm{M}$ & 4 & + & - & - & T4 & - & - & - \\
\hline $83 \mathrm{~F}$ & 3 & + & - & + & $\begin{array}{l}\text { T4 + Paraaortic } \\
\text { lymph nodes }\end{array}$ & - & - & - \\
\hline $85 M$ & 4 & - & + & - & $\mathrm{T} 4$ & - & - & - \\
\hline $48 M$ & 4 & + & - & - & $\begin{array}{c}\text { Hepatic metastasis } \\
+ \text { Paraaortic lymph } \\
\text { nodes }\end{array}$ & - & - & - \\
\hline $74 M$ & 4 & - & + & + & T4 & + & - & - \\
\hline $59 M$ & 4 & - & + & + & $\begin{array}{l}\text { T4 + Hepatic } \\
\text { metastasis }\end{array}$ & + & - & - \\
\hline $31 \mathrm{~F}$ & 4 & Unresectable & - & - & Multiple metastasis & + & - & - \\
\hline $43 \mathrm{~F}$ & 3 & - & + & + & T4 & + & - & - \\
\hline $77 \mathrm{~F}$ & 4 & + & + & + & T4 & - & - & - \\
\hline $64 \mathrm{~F}$ & 4 & Unresectable & - & - & $\begin{array}{c}\text { T4 + Multiple } \\
\text { metastasis }\end{array}$ & - & - & - \\
\hline $56 M$ & 4 & Unresectable & - & - & $\begin{array}{l}\text { T4 + Multiple } \\
\text { metastasis }\end{array}$ & - & - & - \\
\hline $45 \mathrm{~F}$ & 4 & - & + & + & T4 & - & - & - \\
\hline $60 \mathrm{M}$ & 4 & - & + & - & T4 & - & - & - \\
\hline $60 M$ & 4 & - & + & + & T4 & - & + & - \\
\hline
\end{tabular}

$C T$ - chemotherapy, $R T$ - radiotherapy.

tumour perforations (14.1-21\%) [5]. Treatment of perforated colorectal cancer is complicated, and the prognosis is rarely good. Colorectal cancer-related perforation is considered an advanced stage due to the potential of tumour cells to spread to the peritoneum throughout the perforation region [6].

The rate of malignant perforation due to colorectal tumours is between $1.2 \%$ and $9 \%$, and the mortality rate is between $12 \%$ and $48 \%$ despite modern developments in the management of intensive care services [7]. Many studies have demonstrated that patients with perforated colon and rectum tumours have high perioperative mortality, and long-term survival is poor. This poor result is based on many risk factors such as advanced age of patients, degree of peritonitis, septic stage, location of perforation, stage of tumour, cardiopulmonary comorbidities, ASA degree, and presence of distant metastasis [8]. In the study by Mandava et al. [9], 5-year disease-free survival was $14 \%$. In our study the mean follow-up period was 4.2 years and the 3-year survival rate was $44.4 \%(n=8)$.

It is necessary to take the perforated colon tumour out of the abdominal cavity with the related bowel loops. In these cases, because the disease is usually at an advanced stage, resection of tumours requires a very difficult surgical procedure [10]. In our study, perforated tumours could be resected in $77.7 \%$ of the cases. However, residual tumour tissue was left in $42.8 \%$ of these cases. In surgical procedures to be performed by leaving the intestine segment with perforated tumour in the abdomen, almost all of these cases progress due to infection-related complications. Sepsis was the most common cause of mortality in the hospital. Although chemotherapy has significantly improved recently, it may cause thromboembolism, delayed wound healing, bleeding, and perforation, especially in the anastomosis area [11]. Postoperative mortality was observed in $25 \%$ $(n=2)$ of our patients who received chemotherapy. 
Table II. Operative and postoperative outcomes

\begin{tabular}{|c|c|c|c|c|c|c|c|c|}
\hline $\begin{array}{l}\text { Age } \\
\text { gender }\end{array}$ & Diagnosis & $\begin{array}{l}\text { Resection } \\
(1 \text { - full/ } \\
2 \text { - partial) }\end{array}$ & $\begin{array}{l}\text { Number } \\
\text { of lymph } \\
\text { nodes }\end{array}$ & $\begin{array}{c}\text { Number of } \\
\text { positive lymph } \\
\text { nodes }\end{array}$ & $\begin{array}{l}\text { Surgical } \\
\text { border }\end{array}$ & Mortality & $\begin{array}{l}\text { Operative } \\
\text { mortality }\end{array}$ & $P$-value \\
\hline $61 M$ & Recurrent rectum ca & 2 & 22 & 6 & - & + & - & \\
\hline $78 \mathrm{~F}$ & Rectum ca & 1 & 20 & 0 & - & + & + & 0.062 \\
\hline $60 M$ & Rectum ca & 1 & 15 & 1 & - & - & - & \\
\hline $87 \mathrm{~F}$ & Splenic flexure ca & 1 & 5 & 2 & - & + & + & \\
\hline $104 M$ & Cecum ca & 1 & 12 & 3 & - & + & + & \\
\hline $83 \mathrm{~F}$ & Cecum ca & 1 & 18 & 4 & - & - & - & \\
\hline $85 M$ & Cecum ca & 1 & 6 & 0 & - & + & - & \\
\hline $48 M$ & Cecum ca & 1 & 26 & 5 & + & + & + & \\
\hline $74 M$ & Rectum ca & 2 & 1 & 0 & + & - & - & \\
\hline $59 M$ & Sigmoid ca & 1 & 15 & 3 & - & + & + & \\
\hline $31 \mathrm{~F}$ & Recurrent rectum ca & 2 & 15 & 4 & - & - & - & \\
\hline $43 \mathrm{~F}$ & Rectosigmoid ca & 1 & 7 & 0 & - & + & - & \\
\hline $77 \mathrm{~F}$ & Cecum ca & 2 & 2 & 1 & + & + & - & \\
\hline $64 \mathrm{~F}$ & Cecum ca & 1 & 15 & 7 & - & + & + & 0.043 \\
\hline $56 M$ & Cecum ca & 1 & 4 & 0 & - & + & + & \\
\hline $45 \mathrm{~F}$ & Hepatic flexure ca & 1 & 12 & 3 & - & + & + & \\
\hline $60 M$ & Splenic flexure ca & 1 & 13 & 5 & - & + & - & \\
\hline $60 M$ & Rectum ca & 1 & 15 & 4 & - & + & - & \\
\hline
\end{tabular}

The issue of performing anastomosis in the same session after resection in patients with perforated colon cancer is controversial. The reason for this situation is that the operation is performed in emergency conditions, so the contamination of the anastomosis area, the risk of anastomosis leakage, and as a result the morbidity and mortality rates are high [12]. There are studies suggesting use of the Hartmann procedure after perforated left colon cancer surgeries or colostomy after resection. After right hemicolectomy surgeries, primary anastomosis is recommended in the same session [13, 14]. There are also studies indicating otherwise. Biondo et al. [15] reported that primary anastomosis can be performed after resection, except for in patients with high comorbidity, sepsis with faecal peritonitis, and in patients with immune deficiency. Even in cases with diffuse peritonitis, it was reported that primary anastomosis can be performed safely, and mortality and morbidity rates in cases with primary anastomosis do not differ greatly from multi-stage surgical procedures. However, the most important problem in these patients, whose general condition is very bad and systemic effects of intraabdominal infection are seen, is anastomosis leak [16]. Our approach in this regard has been to avoid primary anastomosis in patients with faecal peritonitis.
In cases with localized peritonitis, primary anastomosis was preferred.

Eight $(80 \%)$ of 10 cases with anastomosis leakage had protective ileostomy; also, $20 \%(n=2)$ had primary anastomosis. In the study conducted by Isbister [17], the rate of anastomosis leakage in patients with perforated colorectal cancer was reported as $6.3 \%$. In contrast, the rate of anastomosis leakage in uncomplicated colorectal cancers is reported in the literature below $5 \%$. The overall mortality rate in these patients is very high and is often associated with intra-abdominal infection $[18,19]$. In our study 8 of the patients developed postoperative mortality. Postoperative mortality occurred in half of 4 unresectable cases.

Spontaneous perforation of colon and rectum cancers occurs either in advanced tumours or in cases that have been neglected and remained away from treatment. Faecal contents and tumour cells leaking from perforated bowel loops into the abdominal cavity cause high mortality. Therefore, these patients must be operated. In resected cases, multi-step surgeries involving anastomosis + protective ileostomy reduce postoperative mortality rates [20]. However, in our series the operative mortality rate was $37.5 \%(n=3)$ in patients undergoing protective ileostomy. In addition, unpredict- 
able risks of stoma closure may increase the morbidity rate in multi-step surgeries involving protective ileostomy $[21,22]$.

\section{Conclusions}

Colorectal cancer perforations have a high risk of postoperative mortality. In order not to spread the disease further by pouring the tumour cells from the faecal content and perforation area into the abdominal cavity, the tumoural colonic segment must be resected in these patients. When determining the surgical method, the general condition of the patient, the estimated time from the onset of perforation and the localization of the perforation should be taken into consideration. Partial resection and trephine colostomy should be performed in patients with multiple metastases and poor general condition.

\section{Conflict of interest}

The authors declare no conflict of interest.

\section{References}

1. Kriwanek S, Armbruster C, Dittrich K, Beckerhinn P. Perforated colorectal cancer. Dis Colon Rectum 1996; 39: 1409-14.

2. Alcobendas F, Jorba R, Poves I, et al. Perforated colonic cancer. Evolution and prognosis. Rev Esp Enferm Dig 2000; 92: 326-33.

3. Sawayama H, Tomiyasu S, Kanemitsu K, et al. Colonic perforation due to colorectal cancer: predicting postoperative organ failure with a preoperative scoring system and selecting the optimal surgical method based on the prognosis. Surg Today 2012; 42: 1082-7.

4. Lee IK, Sung NY, Lee YS, et al. The survival rate and prognostic factors in 26 perforated colorectal cancer patients. Int J Colorectal Dis 2007; 22: 467-73.

5. Otani K, Kawai K, Hata K, et al. Colon cancer with perforation. Surg Today 2019; 49: 15-20.

6. Daniels M, Merkel S, Agaimy A, Hohenberger W. Treatment of perforated colon carcinomas-outcomes of radical surgery. Int J Colorectal Dis 2015; 30: 1505-13.

7. Gullino D, Giordano O, Masella M, et al. The single-stage surgery of perforated colon carcinoma. Our experience of 46 cases. Minerva Chir 1999; 54: 127-37.

8. Ogawa M, Watanabe M, Eto K, et al. Clinicopathological features of perforated colorectal cancer. Anticancer Res 2009; 29: 1681-4.

9. Mandava N, Kumar S, Pizzi WF, Aprile IJ. Perforated colorectal carcinomas. Am J Surg 1996; 172: 236-8.

10. Constantin GB, Firescu D, Voicu D, et al. Analysis of prognostic factors in complicated colorectal cancer operated in emergency. Chirurgia 2020; 115: 23-38.

11. Tsai HL, Hsieh JS, Yu FJ, et al. Perforated colonic cancer presenting as intra-abdominal abscess. Int J Colorectal Dis 2007; 22: 15-9.

12. Zielinski MD, Merchea A, Heller SF, You YN. Emergency management of perforated colon cancers: how aggressive should we be? J Gastrointest Surg 2011; 15: 2232-8.
13. Al-Hendal A, Al-Masri W, Al-Mishaan M, Alexander S. Abscess of the abdominal wall resulting from perforated ascending colon cancer. Gulf J Oncolog 2009; 5: 60-3.

14. Biondo S, Parés D, Martí Ragué J, et al. Emergency operations for nondiverticular perforation of the left colon. Am J Surg 2002; 183: 256-60.

15. Biondo S, Jaurrieta E, Martí Ragué J, et al. Role of resection and primary anastomosis of the left colon in the presence of peritonitis. Br J Surg 2000; 87: 1580-4.

16. Menegozzo CAM, Teixeira-Júnior F, Couto-Netto SDD, et al. Outcomes of elderly patients undergoing emergency surgery for complicated colorectal cancer: a retrospective cohort study. Clinics 2019; 74: e1074.

17. Isbister WH. The management of colorectal perforation and peritonitis. Aust N Z J Surg 1997; 67: 804-8.

18. Chen HS, Sheen-Chen SM. Obstruction and perforation in colorectal adenocarcinoma: an analysis of prognosis and current trends. Surgery 2000; 127: 370-6.

19. Baer C, Menon R, Bastawrous S, Bastawrous A. Emergency presentations of colorectal cancer. Surg Clin North Am 2017; 97: 529-45.

20. Anwar MA, D'Souza F, Coulter R, et al. Outcome of acutely perforated colorectal cancers: experience of a single district general hospital. Surg Oncol 2006; 15: 91-6.

21. Asano H, Kojima K, Ogino N, et al. Postoperative recurrence and risk factors of colorectal cancer perforation. Int J Colorectal Dis 2017; 32: 419-24.

22. Ghazi S, Berg E, Lindblom A, Lindforss U; Low-Risk Colorectal Cancer Study Group. Clinicopathological analysis of colorectal cancer: a comparison between emergency and elective surgical cases. World J Surg Oncol 2013; 11: 133.

Received: 15.06 .2020

Accepted: 22.09 .2020 